\title{
Subjetividades públicas juvenis: a construção do comum e os impasses de sua realização
}

Lucia Rabello de Castro. Universidade Federal do Rio de Janeiro.

\section{Resumo}

Neste artigo, toma-se a noção de subjetividade pública como conceito que permite mediar a análise dos processos de construção de si e do "fazer sociedade". Em um primeiro momento, faz-se um percurso analítico que discute a emergência do sujeito público resultado dos processos de ordenação e racionalização, tanto da sociedade como dos modos de produção subjetiva que excluíram determinados sujeitos da construção do comum. Em seguida, por meio da análise de pesquisas empíricas com jovens sobre sua participação política e social, discutem-se os deslocamentos a este modelo de subjetividade pública, quando outros elementos subjetivos e societários vão compor o cenário da realização do comum e seus impasses. A importância destas transformações para a reinvenção da democracia é ressaltada.

Palavras-chave: subjetividade pública, jovens, comum.

\begin{abstract}
Public youth subjectivities: the construction of the common and the impasses of its realization. In this paper, the notion of public subjectivity is regarded as a mediating concept to analyse the processes of self and society construction. In a first analytical move, the emergence of the public subject is discussed as a result of the processes of rationalization and social structuring, both of society as well as of the modes of subjective production, which excluded certain specific subjects from the construction of the common. In a second analytical move, results from empirical research on young people's social and political participation are presented in order to analyse displacements to this model of public subjectivity, when different elements, both societal and subjective, are introduced in the scenario of the production of the common and its impasses. The importance of these transformations for the reinvention of democracy is remarked.
\end{abstract}

Keywords: public subjectivity, youth, common.

\section{Resumen}

Subjetividades públicas juveniles: la construcción del común y los callejones de su realización. En este artículo, la noción de subjetividad pública es considerada como un concepto que permite mediar el análisis de los procesos de construcción de si y del "hacer sociedad". En un primero momento, se hace un recorrido analítico el cuál discute la emergencia del sujeto público resultado de los procesos de ordenación y racionalización, tanto de la sociedad como de los modos de producción subjetiva los cuales han excluido determinados sujetos de la construcción del común. En seguida, por medio del análisis de investigaciones empíricas con jóvenes sobre su participación política y social, son discutidos los desplazamientos a este modelo de subjetividad pública, cuando otros elementos subjetivos y societarios van a componer el escenario de realización del común y sus callejones. La importancia de esas transformaciones para la reinvención de la democracia es resaltada.

Palabras clave: subjetividades públicas, jóvenes, común. 
Estar entre outros e agir com eles ou, até mesmo contra, constitui um aspecto essencial da vida coletiva. Sem dúvida, os grupos humanos não se caracterizam somente pela aglomeração gregária, aspecto encontrado nos grupos infra-humanos, mas pelo fato de que a produção da vida coletiva efetua transformações no mundo ao redor, e no próprio sujeito que dele faz parte, em um processo permanente de renovação de si mesmo e do entorno. A noção de "subjetividades públicas" põe em relevo o modo de como os indivíduos se posicionam - sentem, agem e relatam - em relação ao seu pertencimento à coletividade mais ampla. Sentir-se parte de um conjunto e dele tomar parte, agindo seja para reforçar ou contestar suas práticas e seus valores, nos diz sobre o processo de afiliação simbólica dos indivíduos a uma determinada sociedade ou grupo social. Mas, mais do que isso, o processo de subjetivar-se, em termos públicos, requer a construção do que é, ou deve ser, comum e relevante para todos e todas engendrando ações, discussões, negociações e embates para que este comum se torne público e visível. Assim, o que se torna público atesta sua relevância para a vida coletiva, e neste sentido, vale observar que possui frequentemente caráter normativo na vida social. Cabe notar que nem sempre todos e todas participam igualmente da construção do comum, na sua extensão e complexidade, e, portanto, nem sempre o que é tido como relevante na vida social foi resultado da participação de todos os indivíduos.

A expressão "subjetividade pública" foi utilizada em 1996 por A. Ehrenberg em uma entrevista para o periódico Adolescence (Ehrenberg, 1996). Este autor se interroga como, nas condições contemporâneas de individualismo crescente, o estar junto poderia acontecer sob o imperativo de se ser si mesmo e se construir como distinto dos outros. Antes dele, na sua obra Relações em público: micro-estudos da ordem pública, Goffman (1971) alude ao conjunto de hábitos, costumes e ritos que organizam a experiência pública dos indivíduos que convivem entre si e se orientam em relação a este mundo comum. Embora não se refira especificamente a uma subjetividade pública, Goffman analisa a experiência subjetiva emergente nas relações em público conducentes à manutenção do mundo tal como é.

Diferentemente de Goffman, proponho que a participação no mundo comum põe em movimento o processo de subjetivar-se, no sentido público, que abrange tanto a adesão aquiescente ao que está posto, como também o questionamento da realidade vigente introduzindo ações e disputas para transformá-la. Seguimos
Arendt quando esta autora afirma que o comum advém do fato de que, "a despeito das diferenças de posição e da resultante variedade de perspectivas, todos estão interessados no mesmo objeto" (2004a, p. 67). O estudo das subjetividades públicas enfoca a natureza dos deslocamentos subjetivos demandados pelo processo de identificação com o comum. Diferentemente das identificações que promovem os interesses individuais e a própria sobrevivência, outras identificações levam os indivíduos a se importarem com os destinos dos grupos sociais a que pertencem e com os modos de convivência que aí se estabelecem.

Quando alguns autores (Forbrig, 2005; Stolle \& Hooghe, 2005) se perguntam, por exemplo, se os jovens estão menos propensos a participar da vida política, e afirmam que há uma descrença destes em relação às instituições políticas, deixam a entender, com ou sem razão, que se o laço social dos jovens hoje prescinde da aposta em valores (comuns), como os da democracia e da participação política, a própria vida democrática em sociedade se coloca em perigo. Portanto, o modo de subjetivação pública decorre dos movimentos em prol de se evidenciar o que é relevante na vida coletiva, em distinção ao que é irrelevante.

Em países como o Brasil, a emergência de uma esfera pública não se realizou como nos estados europeus tendo sido frequente a acomodação de interesses privados na esfera pública e a transposição equivalente entre estas duas esferas (Bignotto, 2002; Figueiredo, 1995). As condições culturais e políticas que deram origem à noção de espaço público, e eventualmente ao perfil subjetivo que a ele se adequaria, produziram uma tradição encetada por filósofos europeus, principalmente Jurgen Habermas (1994) e Hannah Arendt (1958/2004a), cuja análise revelou os efeitos potencialmente perniciosos para a esfera pública europeia da difusão da cultura de massas, para Habermas, e da priorização da lógica econômica, para Arendt.

Neste artigo, proponho discutir como a noção de subjetividades públicas pode mediar a conjunção da construção de si e a dilemática convivência coletiva, frente à demanda de produção do comum nas atuais condições brasileiras. O processo de redemocratização no Brasil tem posto em evidência movimentos sociais diversos na busca de "descolonizar a política" (Dagnino, 2000), ainda tida como atividade circunscrita a determinadas práticas e sujeita à regulação de grupos oligárquicos. Proponho seguir dois caminhos analíticos. Em primeiro lugar, retomo alguns aspectos do processo 
de subjetivação que configurou o "homem público" dos tempos modernos, nas sociedades europeias do século XIX, quando o entrelaçamento subjetivo-societário potencializou determinadas disposições subjetivas em detrimento de outras face às exigências do projeto de civilização e progresso. Em segundo lugar, discuto, a partir de um recorrido de pesquisas publicadas sobre participação de jovens, como se condicionam as subjetividades, notadamente as juvenis, implicadas na construção do comum, tendo em vista tanto a crise do sujeito unitário, autocentrado e universal (Critchley \& Dews, 1996; Decca, 2004), como a crise da sociedade integrada e coesa (Sassen, 2010; Touraine, 2010). A pergunta é se, e como, os mais novos buscam realizar sua humanidade para além da mera sobrevivência, criando espaços para compartilhar as histórias sobre a origem, os desenhos coletivos do porvir e a discussão dos pactos de bem viver.

\section{A Emergência do "Homem Público": O Comum Sob a Égide da Razão, do Progresso e da Ordem}

No início do século passado, quando Freud (1930/1996; 1927/1996) buscou compreender como as demandas da civilização incidiam no processo de formação dos sujeitos, não se colocava em questão o destino civilizatório de progresso, nem as formas as formas vigentes de se "fazer sociedade". Parecia evidente que o modo de organização social, cuja configuração deveria ser, no máximo, aperfeiçoada, estava dado. O progresso social e material, a razão esclarecida como princípio universal de regulação institucional e individual e a secularização dos costumes atestavam o desempenho extraordinário a que a humanidade havia chegado, e constituíam valores que deveriam ser assegurados. Mais do que isso, eles constituíam um paradigma civilizatório que deveria ser exportado e imposto às nações colonizadas pelos estados imperiais europeus na primeira metade do século XX, embora algumas de suas contradições tivessem levado, ulteriormente, a guerras e genocídios.

Mesmo que, como notou Freud, houvesse ônus pesados no processo de integração dos indivíduos à sociedade, levando a sofrimento e eventuais adoecimentos psíquicos, os baluartes fundantes de ciência e progresso desta sociedade legitimavam a adesão a ela. Sem dúvida, estava em jogo uma determinada identificação do indivíduo com a sociedade, essa vista como ordenável pelos processos de racionalização que nortearam a consolidação das burocracias modernas. Em contraposição ao espaço doméstico destinado às funções de descanso da vida laboral e das lides da reprodução, consolidava-se gradualmente o espaço da vida pública como aquele destinado à discussão de questões tidas como importantes para todos (Calhoun, 1992; Habermas, 1994). No ambiente da Europa oitocentista, foram os homens adultos das classes burguesas que se ocuparam desta discussão convergentes a interesses de determinadas posição social, gênero e grupo cultural. Assim, crianças, jovens, mulheres, e indivíduos das classes populares foram excluídos deste processo de construção do comum. A cidadania oitocentista configurava uma imagem de cidadão e de sociedade mutuamente aderentes tendo a razão como princípio regulador.

Em Durkheim (1914/1970), o processo de individualização deveria concorrer para a formação do cidadão livre (de qualquer dependência psicológica ou sujeição) de modo que, pela internalização das normas sociais, as tendências egoísticas seriam vencidas, e o homem se integraria paulatinamente à sociedade, assumindo seu lugar de cidadão racional e livre. $\mathrm{O}$ individualismo moral e humanista esposado por Durkheim apontava, como condição da subjetividade pública, a emergência do homem racional universal, epítome dos processos socialização direcionados ao recalque dos instintos e paixões violentas. O desenvolvimento das capacidades universais da razão e da volição (consideradas como pertencentes a todos da espécie humana) habilitariam o indivíduo a ser e agir em público.

Assim, o modo público de ser sujeito deveria aguardar os trâmites de um processo de preparação. Por ele era garantida a convergência entre ideais pessoais e fins sociais: a produção do sujeito público encarnado pelo homem livre, racional e civilizado se acompanha da visão de uma sociedade=societas onde prevalece uma ordem compartilhada de normas e valores e instituições comuns (Mouffe, 1993). O modelo subjetivo implicado no desenvolvimento desta ordem societária se colocou como único, e universal. Variações a este modo público de subjetivação foram tidas como inadequadas e inaceitáveis para a construção de uma sociedade iluminada pela Razão e pela Ciência. Alguns modos foram considerados bárbaros, incivilizados e tribais, como quando os europeus se referiram aos modos de ser e fazer sociedade de outras culturas não europeias (Mandani, 1996); outros foram tidos como imaturos, e não socializados, como as formas de ser da criança (Kulynych, 2001), e por isso mesmo alijadas de participar da construção do comum neste modelo de "fazer sociedade". 
Para as crianças, o caminho da socialização, d'après Durkheim, foi realizado pela família e escola obrigatória (Berger \& Luckmann, 1961), em "zonas protegidas" que dispensaram as crianças e os jovens dos embates em relação à construção do comum. A separação do público e do privado em topos distintos acarretou, para as crianças e adolescentes das classes burguesas ao longo da Modernidade, um processo de subjetivação que delimitou o alcance público de sua ação "privatizando-a" ao circuito das trocas sociais em torno da sobrevivência, no espaço doméstico, e da formação pessoal, no espaço escolar. Com isto, estes espaços deixaram de potencializar modos de subjetivação articulados às questões emergentes da convivência coletiva entre as crianças, e entre elas e os adultos.

No entanto, a vida familiar esteve, e está, longe de constituir um retrato fiel de "um refúgio no mundo sem coração" (Lasch, 1991). O santuário suposto e atribuído à família, e também à escola (Vulbeau, 2001), exacerbou uma visão que minimizou as tensões, conflitos e violências aí presentes, em contraposição às adversidades do âmbito extra-doméstico, da vida pública. Assim, Arendt (1958/2004a; 1954/2005), esposa uma visão conservadora, ao afirmar a impossibilidade de a escola se constituir um espaço público e político. No seu texto Reflexões sobre Little Rock, Arendt (2003/2004b) argumenta contrariamente à exposição das crianças aos dilemas das relações raciais conturbadas nos EUA. Pelo fato de se haver promulgado uma lei que obrigava o acolhimento de crianças negras nas escolas públicas, como uma política de integração social, Arendt assinala a inadequação da medida já que as crianças teriam que enfrentar problemas que pertenciam à sociedade adulta, e não a elas. Resolver o problema do racismo trazendo os conflitos e tensões do mundo público para dentro da escola seria, para a autora, intrometer indevidamente a política em um espaço destinado à transmissão da tradição e à proteção da infância que deveria ter a família e a escola como escudos "contra o aspecto público do mundo" (Arendt, 1954/2005, p. 234). Sem dúvida, este foi um ideal que, longe de estabelecer de fato um lugar para as crianças, serviu mais para alimentar o imaginário de uma infância indefesa, frágil e desprotegida. Este modelo de subjetivação pública considerava a cidadania plena - e o exercício da atividade política que permitia a participação na discussão do(s) comum(ns) - como possível apenas para os adultos, supostamente aptos, cognitiva, emocional e moralmente, para esta tarefa.
Mesmo para o cidadão adulto ordinário o exercício deste fazer sociedade com os demais ficou aquém de uma participação mais plena e ativa nos destinos societários. A ocasional participação política por meio do voto significou o progressivo desinvestimento psíquico da maioria dos cidadãos adultos das disputas e dos embates públicos. Villa (1992), a este propósito, assinala como o sistema político representativo reduziu a esfera pública moderna ao voto e às decisões tomadas no âmbito judicial, transformando o cidadão em um sujeito político passivo. Discuto, também (Castro, 2013) como no Brasil, a educação da prole, no contexto das aspirações nacionais criadas pela instalação da república no Brasil, representou o valor que mediava a causa privada da reprodução da vida com a causa pública e nacional da construção da sociedade. Contribuir com uma (a sua própria) prole educada e cidadã pareceu ser a participação suficiente da burguesia nacional na construção dos destinos do país, e no exercício de uma boa e consciente cidadania. Junto com o trabalho pela sobrevivência, a educação dos filhos circunscreveu a participação cidadã da burguesia, legitimando a circunscrição das causas públicas ao valores do espaço doméstico, "afastando o cidadão das preocupações com o que se vive em comum" (Castro, 2013, p. 53). A especialistas, gestores e políticos delegou-se a tarefa de exercer o cuidado com o mundo.

Assim, por um lado, este modo de fazer sociedade resultou no entrave para que crianças e jovens se identificassem com o comum; por outro, retraiu o adulto preocupado com sua própria sobrevivência e reprodução de se sentir interpelado e participar mais amplamente dos embates públicos da sociedade.

\section{Subjetividades Públicas Juvenis nos Contextos Escolares e da Rua: a Participação dos Jovens e a Construção do Comum}

O enlace com a coletividade se coloca como uma questão de interesse uma vez que as certezas de tempos recentes já não parecem fornecer guias para a ação no presente (Jameson, 1996). Frente às crises do sujeito $e$ da sociedade, a análise das subjetividades públicas de jovens no contemporâneo visa compreender como, e se, os jovens são interpelados por problemas que eles supõem importantes na vida coletiva. De que modo os jovens se sentem convocados a se identificar com a coletividade e com suas questões? Como constroem modos de pertencimento e participação na construção do comum? 
Para responder a estas questões, discuto dois conjuntos de pesquisas sobre jovens e sua participação política e social ${ }^{1}$. Um conjunto diz respeito à participação juvenil em espaços públicos, aqui tomados como espaços extrafamiliares e fora da escola. O outro concerne à participação juvenil nos espaços escolares. A noção de participação de jovens conduz-nos a examinar como eles aderem a valores e causas já postos, mas, também, como disputam com a norma estabelecida no embate de fazer valer outras visões de mundo e sociedade, propondo assim um redimensionamento do comum. As participações juvenis nestes dois espaços nos ajudam na análise do modo diferencial de produção de subjetividades públicas, uma vez que estes espaços são regidos por diferentes modos e normas de convivência que, por sua vez, modulam ações e pertencimentos diversos; ajudam-nos também a problematizar a noção de subjetividade pública enquanto prerrogativa de uma cidadania adulta exercida por sujeitos supostamente aptos: autônomos, livres e racionais (Cockburn, 2007). Ao tomarmos o espaço escolar nos interessa interrogar as linhas de fuga aí presentes, já que neste espaço os jovens são demandados a se preocupar apenas com a aprendizagem de conteúdos que os adultos estabelecem como importantes, espaço que, em princípio, não enseja discussões sobre o que os próprios jovens creem como relevante para suas vidas no presente (Alderson, 1999; Cellier, 2001). Nos espaços públicos extrafamiliares e extraescolares, importa analisar como os jovens buscam o que lhes parece pertinente, seja a própria satisfação e diversão, como também novas pautas e modos de convivência coletiva.

\section{O Comum "Achado" na Rua: Achar o Que se Quer Ser e Achar Onde Se Quer Chegar}

Ao ganhar a possibilidade de transitar por outros grupos, além do familiar, outras identificações importantes vão ser possíveis para os jovens, sobretudo ao iniciarem o processo de ocupar e transitar pela cidade (Castro, 2004). A participação juvenil nas situações além daquelas convencionalmente esperadas, tal como a de frequentar a escola e estudar, apresenta um mundo de novas relações sociais, extrafamiliares, que possibilita a reconstrução de seu lugar no mundo inicialmente forjado no âmbito da jurisdição da casa e da escola. Nas pesquisas com jovens que participavam de coletivos como partidos políticos, associações de estudantes e grêmios (Castro, 2008; Castro \& Mattos, 2009; Castro \& Silva, 2015a; Castro \& Silva, 2015b ; Castro, Pérez, \&
Silva, 2009; Castro, Pérez, \& Silva, 2010), outra ordem de preocupações vai mobilizar suas mentes e corações e coabitar com a preocupação consigo - com seu estudo, trabalho, futuro, encontros amorosos - que, até então, consistiram na demanda social mais importante das suas vidas. $O$ ingresso de jovens nos coletivos analisados apoia-se em vínculos anteriores (amigos, conhecidos, professores), mas nem sempre é o primeiro chamado de um amigo que põe em movimento o desejo do jovem de ganhar outros horizontes e habitar outros espaços de interação. Muitas vezes, na retomada narrativa que os jovens apresentam para dar conta desta adesão fica claro um "não saber" do que eles próprios desejam. O chamado do amigo para participar, a indicação de um professor sobre um evento importante, o estar à toa junto com os outros, uma ou mais uma dessas ocasiões desencadeia o desejo de fazer algo diferente. Uma jovem, ao relatar sobre a sua experiência inicial no grêmio da escola, fala da vontade de "fazer alguma coisa" com os amigos, desejo que surge por estarem juntos no espaço escolar:

[...] surgiu um sentimento entre eu e os meus amigos de que já que a gente passava o dia inteiro na escola, a gente podia aproveitar e fazer alguma coisa. E aí o grupo procurou se informar melhor e decidimos montar o grémio na escola [...] foi uma fase muito boa, porque eu saí do meu mundo, assim. Saí de Nova Iguaçu, sabe? [M., militante de um partido político, itálicos nossos] (Castro \& Mattos, 2009, p. 804).

O desejo compartilhado com os amigos de "fazer alguma coisa" desdobra-se na montagem do grêmio e, gradualmente, ganha o horizonte do que está além de Nova Iguaçu, algo de que ela não poderia supor de início que existisse. Do espaço comum criado por ela e pelos colegas, emerge uma trajetória que a conduz até a militância no partido político.

Vale destacar o aspecto tentativo da ação ao invés de seu planejamento ordenado para obter um resultado final, até porque os jovens não antecipam pontos de chegada: ao se interessar por participar de movimentos dos quais nunca ouviram falar, ou que mal conhecem, os jovens não têm ideia do que vão vivenciar. Sem dúvida, o que está em jogo é o que própria ação desvela, a que lugar, ainda não sabido, ela conduzirá o jovem, disposto, outrossim, a se afastar das expectativas do que deveria estar fazendo "normalmente": estudar, pensar no seu futuro, buscar encontros amorosos. Assim, se o jovem é interpelado a um voo livre no desconhecido, ele o faz porque um conhecido ou um amigo o fez antes dele, 
assegurando que há fruição em algo do qual ainda nada supõe saber. Para estes jovens, fazer parte do grêmio, inteirar-se do movimento estudantil, flertar com o ingresso nas associações estudantis ou partidárias traz a possibilidade de produção de uma realidade no presente, diferentemente daquela a ser conquistada pelos estudos no futuro. Significa poder mostrar a si mesmo o que se é, ou se quer ser, mas fazê-lo por meio da ação conjunta com os demais: planejar e realizar reuniões, campeonatos, manifestações, ir a congressos, convencer pessoas, viajar, gritar palavras de ordem, ações que vão estar diretamente ligadas ao desejo recorrentemente trazido por esses jovens de "transformarem a realidade". Como diz um jovem: "Quero me transformar num protagonista." (Castro \& Mattos, 2009). Interessante notar que ambos os processos - transformação de si e da realidade - são almejados e se desvelam pela própria ação, que é hesitante, "precipitada à medida", tendo nos pares a coadjuvância essencial.

A subjetividade pública que se delineia nas falas dos jovens ganha contornos distintos: ela não se produz como local interno de causas e valores introjetados tidos de antemão como relevantes, nem como um agir que, de modo voluntarista e intelectualista, persegue um objetivo previamente dado, mas como a construção processual e tentativa de si e do que se quer. Bidet, Boutet, Chave, Gayet-Viaud e Méner (2015), nas suas pesquisas sobre a experiência cidadã no espaço público, também notam que as ações dos indivíduos não decorrem das ideias, ou seja, não são o resultado de deliberações em que sua visão de mundo é posta à prova ao escolher agir de determinada maneira. Ao contrário, os autores sugerem que o fio da ação se desencadeia tentativamente "no nível de uma perturbação" ("un trouble"), que suscita a atenção e produz afetamento, mas está longe de determinar seus resultados. No caso dos jovens das pesquisas em tela, eles conseguem resgatar retrospectivamente que o afetamento inicial fez surgir uma atenção a aspectos da realidade antes não notados. Ao se engajar em um projeto de intervenção - grêmio, partido, etc. - os jovens qualificam o que fazem de "transformação da realidade", efeito que só pode ser retrospectivamente apreendido e definido: após terem se deixado experimentar o fazer junto com os demais construindo um campo novo de identificações - com amigos, colegas, valores, mundos e porvires. É por meio da adesão, experimentação e engajamento na ação com os outros que se desvela para o jovem o ator que ele quer ser, e simultaneamente qual realidade, ele quer transformar, e como.
Cabe mencionar o entrecruzamento dos "interesses de si" e o campo dos valores da vida coletiva em vias de descoberta, não como opostos, mas como investimentos que criam tensões permanentes e intensas para as escolhas e o agir dos jovens. Os interesses de si cobrem o que os jovens denominam por vida pessoal - a carreira, o/a namorado/a, os estudos, o trabalho - que modulam as outras identificações no campo mais amplo das interações. A vida pessoal constitui um espectro de valores que deve ser permanentemente atualizado frente às novas demandas e valores da vida coletiva: "E o grêmio, o grêmio ocupa tempo... Então às vezes eu tenho que faltar à aula para ir ao grémio, resolver coisas para o grémio [...] Eu consigo conciliar. Mas é uma coisa que pesa..." [C., membro de um grémio]. (Castro \& Mattos, 2009, p. 807)

Eu gosto muito, sempre me diverti muito, eu fiz muitos amigos, fiz a parte partidária com a parte divertida, sabe? Acho que isto é importante [...] E normalmente a sociedade põe prioridade na sua vida particular. Eu naturalmente botei minha prioridade na política, e não foi um dia que eu cheguei e falei "hoje eu vou priorizar política". Não, eu naturalmente faço a política uma prioridade mesmo... [L., presidente de grémio e militante do PT, itálicos nossos]. (Castro \& Mattos, 2009, p. 809)

Nestes dois depoimentos, vale notar como os interesses de si e as causas se tensionam, e às vezes se misturam, a ponto de deixar a vida pessoal ser invadida pelas causas, assim como de tornar as causas mais flexíveis e aderentes à vida íntima. Talvez ao não separarem o público e o privado como lugares distintos, nem isolarem as formas de ser nestes espaços, encontram a possibilidade de conciliação e convergência entre os interesses de si e as causas públicas da vida coletiva.

Quando investigamos outros tipos de coletivos juvenis, cuja participação visava o trabalho de cunho social e comunitário (Castro, 2010a; Castro \& Silva, 2015b; Castro, Pérez, \& Silva, 2009; Silva \& Castro, 2013), são os efeitos da ação que aportam a legitimidade de se vincular a grupos fora do espaço doméstico. Fazer algo que tenha impacto no presente, visibilizando mudanças nas situações de injustiça social, e "resistindo aos apelos da individualização" (i.e. os interesses de si), constituem aspectos centrais da identificação juvenil com estes espaços fora do lar. Nestes grupos diversos (cursos de pré-vestibular comunitários, reforços escolares comunitários, capoeira, radio comunitária, projetos agroecológicos) se buscam ações para alterar situações de injustiça e opressão, 
mesmo que apenas de modo local e incipiente, cujos sentidos e compreensões do que se faz e porque se faz variam, sejam caracterizados como uma ação para a cidadania, como solidariedade, ou até como uma ação micropolítica. Em que pese o ativismo destas iniciativas, o que se destaca é o adensamento do sentido do presente, não como passagem, ou transição a algo ulterior, mas algo como um acontecimento (Peñafiel, 2012). Ao nomearem o que fazem, seja por que significante for, os jovens reiteram a força do sentimento de responsabilidade que os move frente ao sofrimento alheio. Novamente, a subjetivação em curso não enseja tornar pública e compartilhada uma visão de mundo pré-estabelecida, mas de promover a construção de experiências comuns desencadeadas pela indignação frente ao sofrimento alheio. Assim, as emoções de se sentir afetado e responsável por uma situação propulsionam esta subjetividade pública cujo saber, como constata Critchley (2007), advém de poder ser afetado. Diz o autor, "a consciência advém do processo de dilaceramento do sujeito frente às demandas do outro" (p. 11). No caso destes jovens, a visão da injustiça os "dilacera", fazendo-os propícios a construir outros espaços de convivência baseados em valores de justiça e equidade.

É interessante observar que mesmo em coletivos em que os jovens se reúnem para o lazer - dançar, ouvir música eletrônica e consumir drogas - investigados por Riley, More e Griffin (2010), há uma compreensão de que nestes coletivos, como espaços de convívio, amizade, socialidade, se devem cultivar valores como "cuidar do outro", e "responsabilizar-se por ele". Assim, no divertir-se junto e fazer o que se quer, emergem igualmente normas de solidariedade. Por meio dos laços identificatórios extrafamiliares pode-se criar um espaço comum de se viver tal como se deseja que o mundo seja. Nestes grupos, os jovens tentam estabelecer "de baixo para cima" um âmbito restrito de contestação à ordem vigente em espaços circunscritos. A proposta implícita caracteriza-se por uma "uma cidadania do prazer e do consumo" (p. 47), em oposição à cidadania vigente do dever e do trabalho, e formas de solidariedade e responsabilidade acompanham a experiência compartilhada de fruição.

A construção de um comum nos coletivos juvenis investigados, seja pela pauta da "transformação da realidade", seja de outras mais específicas e locais, ampara-se e adquire sentido na construção mesma de uma vivência afetiva compartilhada com amigos e parceiros onde a causa comum, nos seus aspectos ideológico-discursivos, é produzida a partir da força criativa de um vivido coletivamente. Sem dúvida, o "fazer sociedade" é experimentado no seu nível micro, das relações entre pares, que possibilita intuir a partir daí as relações mais amplas. A subjetividade pública decorre, portanto, dos interstícios que se criam na realidade de competição, individualização, ordem e dever em favor de outras pautas de convívio; ao mesmo tempo, a subjetividade é precipitada pela ação não planejada, aberta à contingência que os afetos e emoções possam produzir, e no fio da navalha das tensões dos interesses de si e das adesões ao comum. Este processo de subjetivação põe em relevo a experiência de coletivizar por meio da qual os jovens pretendem, em primeiro lugar, vivenciar as emoções de forma compartilhada, com o outro e na condição de estar com ele. A adesão ao coletivo não se faz exatamente pelo consentimento racional em participar e se solidarizar com uma noção abstrata de humanidade universal. O que parece estar em questão é uma vivência de confiança no outro que traz a possibilidade de vislumbrar sentidos para "fazer sociedade" e novas orientações para agir no mundo.

\section{A Individualização do Sofrimento e a Negação do Comum: o Contexto Escolar e as Subjetividades Públicas}

Aqui tomamos o conjunto de pesquisas sobre a participação de jovens em contextos escolares, para investigar as possibilidades de que esta participação conduza à construção de pautas comuns e à produção de subjetividades públicas. Diferentemente do que vimos anteriormente, na escola os jovens estão posicionados de antemão às expectativas e demandas do processo formal de aprendizagem. Além disso, existe uma obrigatoriedade de que participem das atividades do projeto de formação que lhes é imposto sem que frequentemente possam manifestar se o reconhecem como relevante, importante e interessante para suas vidas.

Em pesquisas realizadas sobre participação dos jovens na escola (Castro, 2006; Castro, 2007; Castro, 2012a; Castro, 2012c; Castro, 2013; Castro, 2014; Castro \& Nascimento, 2013; Castro, 2010b), há um reconhecimento formal da parte deles sobre a importância do projeto de formação. Neste sentido, parece que a adesão ao projeto comum da sociedade, a preparação para o futuro, já os posiciona em um lugar de aquiescência e subordinação. No entanto, sua adesão subjetiva à posição formal de aprender e estudar está frequentemente acompanhado de queixas sobre situações de desrespeito e injustiça na escola. Quando os jovens relatam ser desrespeitados 
pelos professores incluem uma variedade de situações, desde, nas suas palavras, "não ser escutado", "ser punido injustamente", "usar banheiros sujos e carteiras quebradas", "obedecer regras porque são regras", até "não ter aulas porque na escola não tem professor para dar aquela matéria" (Castro, 2010b).

Sentir-se diminuído, inferiorizado e negligenciado compõe uma estrutura sentimental de revolta, raiva e apatia. Em um número enorme de escolas, estes sentimentos e emoções criam um clima de hostilidade e desconfiança dos jovens em relação aos adultos (Almada, 2013; Mattos, Pérez, Almada, \& Castro, 2013; Silva, 2008). Acompanhar as vicissitudes destas emoções possibilita averiguar sua potência na construção de pautas comuns por parte dos estudantes, e seu papel de mediar ações de transformar a realidade vigente. A falta sistemática de um professor, situação frequente nas escolas públicas, foi uma das situações analisadas (Castro \& Nascimento, 2013; Castro et al., 2010), fazendo surgir emoções e ações diversas. É uma questão que atinge o conjunto dos estudantes, e os prejudica enormemente. Os encaminhamentos dados pelos estudantes refletem, principalmente, a negação de um comum que os une: buscar uma explicadora em casa; ou, esperar que um dia este professor apareça. Quando o reclamar acontece, é em geral feito de forma individualizada, ou em grupinhos pequenos que buscam a direção para dar queixa. Outras reações caracterizam-se mais pela impotência e o desânimo, "não querer saber" ou, "desistir de reclamar", "protestar não adiantou nada". Muitas vezes, os alunos acabam desmerecendo as tentativas de construírem uma resposta comum, qualificando-as de "protestos idiotas", ou mesmo como "ato de imaturidade", identificando-se com o que as professoras afirmam deles. Ou então, ao anteciparem as dificuldades desta experiência ser levada à frente no âmbito de uma relação de desvantagem, acabam por qualificar o protesto coletivo como inatingível, sendo ele somente possível se "liderado por alguém muito inteligente", "que tenha boas ideias", ou, "com muitos alunos juntos, o que é difícil".

Nestes diversos encaminhamentos, afirma-se a lógica do projeto de formação como fundada na competência e no desempenho individuais, ou seja, aprender depende da habilidade e recursos internos de cada um que se afirmarão seja qual for o contexto. Ainda que todo o processo de formação do aluno se determine por condições coletivamente engendradas, o jovem que não tem o professor sente que deve fazer algo, mas "para salvar a própria pele", para que ela, individualmente, não se dê mal no final, e não fique reprovada. Sem dúvida, algumas vezes os jovens vislumbram que se fizerem algo juntos, têm mais chances de resolver o problema de cada um. Só que esta ação coletiva permanece mais imaginada do que atuada na realidade ao anteverem e se amedrontarem diante das inúmeras dificuldades desta ação. Os estudantes se dão conta, ainda que de modo pouco claro, de que a ação empreendida coletivamente levaria a uma confrontação de posições, a dos estudantes contrapondo-se à direção, fazendo emergir a posição coletiva dos estudantes, e sua questão coletiva, sua causa comum. Nos seus relatos evidencia-se, contudo, que o impulso à ação se torna enfraquecido e capturado ao se autorrotularem o que são antes de agir (apenas alunos imaturos, sem força, que fazem protestos idiotas) em vez de serem impulsionados pelo que sentem. Assim, as questões da convivência coletiva na escola desencadeiam emoções que não propulsionam nem a indignação, e nem a denúncia, se quisermos acompanhar Boltanski (2008), na sua descrição das emoções e gestos políticos por excelência. Todavia, é importante observar que é o vislumbre imaginário e possível de uma ação coletiva por parte dos alunos que lhes dá a possibilidade de se produzirem subjetivamente fora da órbita da subordinação da posição de aluno.

Os estudantes relatam que protestos e abaixo-assinados podem dar errado, ou não mudam nada, as mudanças dependem de capacidades pessoais extraordinárias, só um super-homem pode ser capaz de desafiar e enfrentar o status quo. Os jovens acabam se acomodando nas frustrações e nas insatisfações, buscando soluções individualizadas para evitar o prejuízo das aulas ruins, da falta de professores, do banheiro que não funciona. Deste modo, a transmissão acaba sustentando a ilusão de que embora, na origem, o sofrimento seja de todos os jovens, e a falta de cuidado dos mais velhos se enderece a todos e todas, poderá haver salvação para os mais talentosos, os mais espertos. Esses podem se autorresgatar do dano moral a todos infligidos. Assim, a solução individualizada vai ao encontro do que Kehl $(2000$, p. 34) aponta como "o recalque do caráter coletivo do que determina nossos atos", daquilo que se precisa resgatar coletivamente - o sofrimento comum - para se poder agir.

Nestas condições os jovens constroem, por certo, determinadas identificações com as demandas sociais que lhes são impostas. O discurso dos interesses de si, tais como, nas palavras dos estudantes, "estudar para se dar bem na vida", "ter um emprego legal", "não ser lixeiro", (Castro, 2006; Castro, 2007; Silva, Bacelar, \& 
Castro, 2012) cumprem efetivamente a possibilidade de sua participação na sociedade, tal como lhes é oferecida e definida. Contudo, este "fazer sociedade" implica precipuamente uma resposta de se enquadrar à demanda de estar incluído pelo trabalho e consumo, e neste sentido, a subordinação completa do indivíduo à realidade posta sem que se possa, ou recusá-la, ou recriá-la.

Quando estas pesquisas se debruçam sobre as relações entre pares (Castro, 2014; Libardi \& Castro, 2014), se constata que essas relações constituem o sentido mais importante de se estar na escola: encontrar com os amigos, conversar com eles e fazer esporte constituem o "estado de graça" da escola, propiciando uma importante economia de trocas, afetos e paixões que, em geral, passa ao largo do que se visibiliza como central e importante na vida escolar. No entanto, esta economia afetual permanece à deriva tanto do olhar do adulto, como da institucionalidade escolar. Entretanto, tal potência afetiva e pulsional contribui para as poucas tentativas dos jovens de, por exemplo, reativar uma rádio dos alunos; iniciar atividades conjuntas de dança, música e grafite; organizar campeonatos de handebol; promover lanches coletivos; além de conduzir ações de resistências a intimidações de professores, boicotes à prova do Sistema de Avaliação da Educação do Estado do Rio de Janeiro [SAERJ], e mobilizações para aumentar o tempo de recreio. Estas tentativas tendem a ser erráticas, temporárias e casuais, mas encorpam algumas causas comuns que fazem a realidade escolar mais próxima e amena ao que os próprios jovens acham relevantes para suas vidas. Outras tentativas aparecem a reboque de iniciativas institucionais, como torneios de dança da escola, e festas comemorativas, e, frequentemente, fornecem oportunidades para os jovens se experimentarem como um grupo com diferenças, conflitos e simpatias.

Nota-se que, apesar de esparsas, pouco consistentes e efêmeras, estas mobilizações apontam para um recurso potente para os jovens constituírem um espaço público de trocas entre iguais e a partir de sua posição singular de sujeito na escola: um espaço que propicia a construção e negociação de outros valores e pautas de convivência na escola. Deste lugar, tentativamente construído, os jovens podem vivenciar alguns conflitos e os dilemas da vida pública da escola, assim como as agruras e as apostas de um enlace com um coletivo mais amplo, o de seus próprios pares. Todavia, estas iniciativas permanecem um aspecto marginal na vida escolar que ainda não é considerado como significativo para o conjunto do processo de transmissão.

\section{Considerações finais}

O panorama que se descortina nestas pesquisas mostra que os jovens, seja na rua, seja na escola, embora de maneiras distintas, constroem valores e causas a respeito do que lhes importa e do que acham relevante na vida coletiva. A escola, por exemplo, longe de ser um contexto de proteção contra os males do mundo público e de preparação para ele, não oportuniza que situações de injustiça sejam discutidas fomentando o diálogo democrático, a adesão consciente às normas e seu possível questionamento. Neste sentido, a potência das situações de humilhação, desrespeito e injustiça que ocorrem aí encontram saídas que reforçam a privatização das aflições individuais e não conduzem à sua transformação em sofrimento social cujas determinações coletivas possam ser vislumbradas. A subjetividade pública ensejada nestas condições adere à proposta racionalizante do desempenho escolar como um meio de obter sucesso pessoal - emprego, remuneração - no futuro, sob a promessa da integração do jovem à sociedade tal como ela é. Mesmo assim, os jovens conseguem fazer uso da exuberante economia afetual da relação entre pares na escola para fazer valer a construção de "pequenas causas", aquelas que introduzem modos de convivência e valores mais próximos de como gostariam de viver a experiência escolar como jovens nas condições do mundo contemporâneo. Assim, ainda que estas ações pareçam erráticas e incipientes, elas assinalam uma deriva de sua posição de subordinação que os coloca como recebedores aquiescentes da atenção e autoridade adulta.

É no âmbito de suas ações fora do contexto escolar que os jovens acham suas possibilidades de construção de um comum, quando, então, fora das injunções da relação de subordinação do contexto escolar, podem experimentar a descoberta do mundo desconhecido e construir formas de viver com os demais. As pesquisas sobre a participação de jovens em coletivos organizados formalmente (partidos, associações estudantis, grêmios) ou informais (atividades coletivas de trabalho solidário) mostram que estas ações juvenis se apoiam na vivência do grupo de pares, aspecto essencial do modo de produção de sua subjetividade pública. Todavia, este aspecto, além de reiterar a relevância do outro semelhante na constituição do eu adolescente, aponta elementos singulares a respeito de como a adesão e construção de um comum se desenvolve. Cabe destacar que se trata de uma subjetividade passível de ser afetada e convocada, portanto, aberta diante de um mundo no qual os jovens 
têm cada vez menos referências e certezas de como agir e porque agir, quando prevalecem os imperativos de se fazer por si mesmo e a partir de si próprio (Beck \& Beck, 2009). Esta abertura implica deixar-se capturar pelo que não se sabe de antemão, pelo que não pode ser ainda planejado como ponto de chegada, e por quais desdobramentos a ação se curvará. Nesta veia, as ações dos jovens assumem um caráter tentativo, criando interstícios no presente e no agora por onde podem retrospectivamente dar sentido ao que fazem. Diferentemente de estar na posição de deliberar para saber agir, sua ação que se precipita faz emergir os sentidos deste agir e de quem se é. O caráter tentativo e, porque não, precário, do mundo que se quer criar, seja na militância, no engajamento solidário ou na "cidadania pelo prazer", evidencia um "fazer sociedade" cuja visão está aquém da sociedade antes totalizada como coesa e unitária, e que agora se delineia como fragmentada, inacessível na sua totalidade e de futuro incerto.

Vale notar também o encaminhamento que os jovens dão às tensões oriundas do confronto dos interesses de si e a construção de pautas comuns. Face aos ditames da competição avassaladora promovida pela globalização neoliberal, coloca-se para os jovens a demanda de ter que "resistir à individualização" para perseguir simultaneamente a construção de si e as preocupações com a vida que se quer em comum. Um campo interno de conflitos surge, não encontrando soluções prontas, nem válidas para todas, cada escolha está imersa em dilemas cujo desenlace evidencia a produção de uma subjetividade pública que não se aparta de seu nicho privado, mas nele se mistura. Assim, no que pudemos observar a subjetividade pública não responde por uma maneira distinta de ser e sentir, acionada pelo fato de o jovem se encontrar em um espaço público, mas é aquela que, como coloca Mouffe (1993), é privada e pública ao mesmo tempo, uma vez que as ações são públicas porque se vinculam a modos e condições requeridos pelas pautas coletivas de convivência, e os desejos, escolhas e responsabilidades são privados, porque são atributos do espaço íntimo de cada um. Ressalta-se a qualidade agônica desta subjetividade pública não somente por conta dos embates decorrentes da convivência coletiva, mas também pelo fato de que os desejos e escolhas dos indivíduos compõem um elenco mutuamente conflitante de identificações, algumas relativas aos interesses de si, e outras que concernem aos interesses da coletividade. Estes devem, eventualmente, prover satisfações e prazer pessoais da mesma forma como se os supõe obter por meio do investimento nos interesses de si.

A discussão sobre subjetividades públicas aponta para a importância de se pensar hoje a democracia e o ideal que ela coloca de uma autonomia coletiva (Castoriadis, 1997) em que todos e todas são convocados a participar ativamente da construção da vida coletiva. Se na emergência das democracias modernas a subjetividade pública requerida excluía os jovens e as crianças, entre outros, e determinava credenciamentos explícitos para a cidadania plena, então, as sociedades permaneceram longe de se democratizar suficientemente. $\mathrm{O}$ que podemos aprender com as experiências juvenis de participação nos conduz a interrogar tanto sobre os limites e as formas que se impuseram à vida pública que têm restringido possibilidades de reinvenção dos ideais democráticos, como sobre as concepções do que é ser jovem ou ser adulto hoje.

\section{Referências}

Alderson, P. (1999). Human rights and democracy in schools: do they mean more than 'picking up litter and not killing whales'? The International Journal of Children's Rights, 7, 185-205. doi: 10.1163/15718189920494336

Almada, C.V. R. (2013). A experiência de ser aluno hoje: explorando as mobilizações afetivas de alunos frente às demandas da escola (Dissertação de Mestrado). Universidade Federal do Rio de Janeiro, Rio de Janeiro. Recuperado de http://objdig.ufrj.br/30/teses/807927.pdf

Arendt, H. (2004a). A condição humana. Rio de Janeiro, RJ: Forense Universitária. (Obra original publicada em 1958)

Arendt, H. (2004b). Reflexões sobre Little Rock. In Responsabilidade e julgamento (pp. 261-281). São Paulo, S.P.: Schwarcz. (Obra original editada e publicada por Jerome Kohn em 2003)

Arendt, H. (2005). Entre o passado e o futuro. São Paulo, S.P.: Perspectiva. (Obra original publicada em 1954)

Beck, U., \& Beck-Gernsheim, E. (2009). Individualization. Londres, U.K.: Sage.

Berger, P., \& Luckmann, T. (1961). The social construction of reality: a treatise in the sociology of knowledge. Nova lorque, NY: Doubleday.

Bidet, A., Boutet, M., Chave, F., Gayet-Viaud, C., \& Méner, E. (2015). Publicité, sollicitation, intervention. Sociologies. Recuperado de http://sociologies.revues.org/4941

Bignotto, N. (2002). Entre o público e o privado. In I. Domingues, P. R. M. Pinto \& R. Duarte (Orgs.), Ética, política e cultura, (pp. 281-297). Belo Horizonte, M.G.: UFMG.

Calhoun, C. (1992). Habermas and the Public Sphere. Cambridge: MIT Press.

Castoriadis, C. (1997). World in fragments. Stanford, CA.: Stanford Univ. Press.

Castro, L. R. de (2004). A aventura urbana - crianças e jovens no Rio de Janeiro. Rio de Janeiro, R.J.: 7Letras/Faperj. 
Castro, L. R. de (2006). Vicissitudes da subjetivação politica juvenil na contemporaneidade. Revista Psicologia Política, 6(11), 13-34.

Castro, L. R. de (2007). Political participation in the school context: youth experiences in collective action. Children, Youth and Environments, 17(2), 93-111.

Castro, L. R. de (2008). Participação política e juventude: do mal-estar à responsabilização frente ao destino comum. Revista de Sociologia e Política, 16(30), 253-269. doi: 10.1590/S0104-44782008000100015

Castro, L. R. de (2010a). Etre jeune: une puissance incertaine dans l'espace public brésilien. In A. Petitat (Org.), Être en société. Le lien social à l'épreuve des cultures (pp. 135-152). Québec, Canadá: Presses Universitaires de Laval.

Castro, L. R. de (2010b). Falatório: participação e democracia na escola. Rio de Janeiro, R.J.

Castro, L. R. de (2012a). The good-enough society, the good-enough citizen and the good-enough student: where children's participation agenda is moving to in Brazil? Childhood, 19(1), 52-68. doi: $10.1177 / 0907568211402525$

Castro, L. R. de (2012c). Entre a subordinação e a opressão: os jovens e as vicissitudes da resistência na escola. In C. Mayorga, L. R. de Castro, \& M. A. Prado (Orgs.), Juventude e a experiência da política no contemporâneo, (pp. 63-98). Rio de Janeiro, R.J.: Contracapa.

Castro, L. R. de (2013). O futuro da infância: os impasses nas relações intergeracionais e das crianças com seus pares. In L. R. de Castro (Org.), O futuro da infância e outros escritos, (pp. 15-36). Rio de Janeiro, R.J.: 7Letras/Faperj.

Castro, L. R. de (2014). Challenges to children's autonomy in a Brazilian state school. The Oriental Anthropologist, 14(2), 237-250. Recuperado de http://crawl.prod.proquest.com.s3.amazonaws.com/ fpcache/a146857a4706266bd1a95d7d04e4a76a.pdf?AWSAcces sKeyld=AKIAJF7V7KNV2KKY2NUQ\&Expires $=1458765697 \&$ Sign ature $=$ nG8MCnyDOBloFY3vfvmlJTjnOKk\%3D

Castro, L. R. de, \& Mattos, A. (2009). O que a política tem a ver com a transformação de si? Considerações sobre a ação política a partir da juventude. Análise Social XLIV (193), 787-817. Recuperado de http://analisesocial.ics.ul.pt/documentos/1260461328M1jFM7cp0 El76KE1.pdf

Castro, L. R. de, \& Nascimento, E. M. (2013). Politizar as relações entre jovens e adultos? A construção da experiência escolar pelos estudantes. Estudos de Psicologia, 18(2), 359-367. doi: 10.1590/ S1413-294X2013000200023

Castro, L. R. de, \& Silva, C. S. (2015a). L'action politique des jeunes étudiants au Brésil aujourd'hui : le présage de la fin d'une époque? BRÉSIL(S). Sciences Humaines et Sociales, 7, 39-58. doi: 10.4000/ bresils. 1431

Castro, L. R. de, \& Silva, C. S. (2015b). Brazilian youth activism: in search of new meanings for political engagement? Alternatives - Local, Global, Political, 39(3), 187-201. doi: 10.1177/0304375415569389

Castro, L. R. de, Pérez, B., \& Silva, C.S. (2009). “Trabalho solidário”: Em busca de outros valores para a participação política. Praia Vermelha, 19(1), 109-124. Recuperado de https://docs.google.com/file/d/0B0-tS_Kbeq-ZGZQN3R3TEc0aGs/edit?pref=2\&pli=1

Castro, L. R., Pérez, B. C., \& Silva, C. S. (2010). Os jovens no trabalho solidário: novos rumos da participação politica? Juventude.br (Centro de Estudos e Memória da Juventude), 5(9), 42- 47. Recuperado de http://www.cemj.org.br/revistasPdf/revista_juventude_Jun_2010.pdf

Calhoun, C. (1992). Habermas and the public sphere. Cambridge, Mass.: MIT.
Céllier, H. (2001). Citoyenneté, école et projets fédérateurs: nouvelle cohérence sociale? Quelle citoyenneté à l'école? In A. Vulbeau (Org.), La jeunesse comme ressource, (pp.187-198). Paris, França: Ėres.

Cockburn, T. (2007). Partners in power: a radically pluralistic form of participative democracy for children and young people. Children and Society, 21, 446-457. doi: 10.1111/j.1099-0860.2006.00078.x

Critchley, S. (2007). Infinitely demanding. ethics of commitment, politics of resistance Londres, U.K.: Verso.

Critchley, S., \& Dews, P. (1996). (Orgs.). Deconstructive subjectivities. Nova lorque, NY.: State University of New York Press.

Dagnino, E. (2000). Cultura, cidadania e democracia: a transformação dos discursos e práticas na esquerda latino-americana. In S. Alvarez, E. Dagnino, \& A. Escobar (Orgs.), Cultura e política nos movimentos sociais latino-americanos: novas leituras, (pp. 61-102). Belo Horizonte, M.G.: UFMG.

Decca, D. (2004). A crise da razão na modernidade. In A. Duarte, C Lopreato, \& M. B. Magalhães (Orgs.), A banalização da violência: a atualidade do pensamento de H. Arendt, (pp. 287-294). Rio de Janeiro, R.J.: Relume Dumará.

Durkheim, E. (1970). La science sociale et l'action. Paris, França: PUF. (Obra original publicada em 1914)

Ehrenberg, A. (1996). Subjectivité publique. Interview d'Alain Ehrenberg par M. Askevis, M.C.

Figueiredo, L. C. (1995). Modos de subjetivação no Brasil e outros escritos. São Paulo, S.P. Escuta.

Forbrig, J. (2005). (Org.). Revisiting youth political participation: challenges for research and democratic practice in Europe. Strasbourg, França: Council of Europe Publishing.

Freud, S. (1996). O futuro de uma ilusão. Obras completas de S. Freud, (Vol. 11, pp.15-66). Ed. standard brasileira. Rio de Janeiro, R.J.: Imago (Obra original publicada em 1927)

Freud, S. (1996). O mal-estar da civilização. Obras completas de $S$. Freud, ed. Standard brasileira, (Vol. 11, pp. 73-150). Rio de Janeiro, R.J.: Imago (Obra original publicada em 1930)

Goffman, E. (1971). Relations in public. Microstudies of the public order. London, U.K.: Penguin.

Habermas, J. (1994). The Structural transformation of the public sphere. Cambridge, Mass.: Polity.

Jameson, F. (1996). O Marxismo Tardio: Adorno ou a persistência da dialética. São Paulo: UNESP.

Kehl, R. (2000). Existe a função fraterna? In R. Kehl (Org.), Função fraterna (pp. 31-48). Rio de Janeiro, R.J.: Relume Dumará.

Kulynych, J. (2001). No playing in the public sphere: democratic theory and the exclusion of children. Social Theory \& Practice, 27(2), 231264. Recuperado de http://www.jstor.org/stable/23562064

Lasch, C. (1991). Refúgio num mundo sem coração. A família: santuário ou instituição sitiada?(I. Tronca \& L. Szmrecsanyi, Trads.). Rio de Janeiro, R.J.: Paz e Terra.

Libardi, S., \& Castro, L. R. de (2014). 'Violencias sutis': jovens e grupos de pares na escola. Fractal: Revista de Psicologia, 26(3), 943-962. doi: 10.1590/1984-0292/1237

Mandani, M. (1996). Citizen and subject. Princeton, N.J.: Princeton Univ. Press.

Mattos, A., Pérez, B., Almada, V., \& Castro, L. R. de (2013). O cuidado na relação professor-aluno e sua potencialidade política. Estudos de Psicologia, 18(2), 369-377. doi: 10.1590/S1413-294X2013000200024 
Subjetividades públicas juvenis: a construção do comum e os impasses de sua realização

Mouffe, C. (1993). Citizenship and the political community. In C. Mouffe (Org.), The return of the political (pp. 60-73). Londres, U.K.: Verso.

Peñafiel, R. (2012). Les actions directes spontanées au-delà du virage à gauche. In A. Corten, C. Huart \& R. Peñafiel (Orgs.), L'interpellation plébéienne en Amérique Latine, (pp.11-31). Québec, Canadá: Presses de L'Université de Québec/Ed. Karthala.

Riley, S., More, Y., \& Griffin, C. (2010). The pleasure citizen: analysing partying as a form of social and political participation. Young, 18(1), 33-54. doi: 10.1177/110330880901800104

Sassen, S. (2010). Ver une multiplication d'assemblages spécialisés de territoire, d'autorité et de droits. In A. Petitat (Org.), Être en société. Le lien social à l'épreuve des cultures (pp. 63-80). Québec, Canadá: Presses Universitaires de Laval.

Silva, C. S., \& Castro, L. R. de (2013). Para além das fronteiras convencionais do ativismo político: a inserção de jovens em "coletivos fluidos". In H. Bezerra \& S. Oliveira (Orgs.), Juventude no século XXI: dilemas e perspectivas (pp. 7-38). Goiania, GO: Canone Editorial.
Silva, C. S., Bacelar, R. P., \& Castro, L. R. de (2012). Ação coletiva e os valores da vida escolar. In C. Mayorga, L. R. de Castro \& M. A. Prado (Orgs.), Juventude e a experiência da política no contemporâneo (pp. 169-200). Rio de Janeiro, R.J.: Contracapa.

Silva, M. (2008). Convivência e participação: fios e desafios na educação na contemporaneidade (Tese de Doutorado não publicada). Universidade Federal do Rio de Janeiro, R.J.

Stolle, D., \& Hooghe, M. (2005). Inaccurate, exceptional, one-sided or irrelevant? The debate about the alleged decline of social capital and civic engagement in western societies. British Journal of Political Sciences, 35, 149-167. doi: 10.1017/S0007123405000074

Touraine, A. (2010). Après la fin du social. In A. Pétital (Org.), Être en société. Le lien social à l'épreuve des cultures (pp. 15-30). Québec, Canadá: Presses Universitaires de Laval.

Villa, D. (1992). Postmodernism and the public sphere.American Political Science Review, 86(3), 712-721. doi: 10.2307/1964133

Vulbeau, A. (2001). La jeunesse comme resource. Expérimentations et expérience dans l'espace public. Paris, França: Ėres.

${ }^{1}$ Estas pesquisas dizem respeito a uma trajetória de investigação realizada ao longo da última década sobre participação política e social de crianças e jovens cujos trabalhos foram, na sua maior parte, publicados. Trata-se, aqui, portanto, de retomar esta trajetória e analisa-la sob o prisma da noção de subjetividade pública que, até então, não tinha sido incluída nas preocupações que direcionaram estas pesquisas.

Lucia Rabello de Castro, Doutora em Psicologia pela Universidade de Londres, Pós-Doutorado no Centre for the Study of Developing Societies, Delhi (India), é Professora Titular Instituto de Psicologia e do Programa de Pós-graduação em Psicologia da Universidade Federal do Rio de Janeiro (UFRJ). Endereço para correspondência:

Av. Rui Barbosa, no 40, Apto 902. Rio de Janeiro - RJ, CEP:22.250- 020. Telefone: (21)2553-8251/(84)99918-4485. E-mail: Ircastro@infolink.com.br 